\title{
Impact of point-of-care ultrasound on quality of care in clinical practice
}

This article was published in the following Dove Press journal:

Reports in Medical Imaging

5 September 2014

Number of times this article has been viewed

\author{
Srikar Adhikari' \\ Richard Amini' \\ Lori A Stolz' \\ Michael Blaivas ${ }^{2}$ \\ 'Department of Emergency \\ Medicine, University of Arizona \\ Medical Center, Tucson, AZ, \\ ${ }^{2}$ Department of Internal Medicine, \\ University of South Carolina School \\ of Medicine, Columbia, SC, USA
}

Correspondence: Srikar Adhikari Department of Emergency Medicine, University of Arizona Medical Center, PO Box 245057, Tucson, AZ 85724, USA

$\mathrm{Tel}+\mathrm{I} 5206269604$

Fax +I 5206262480

Email sriadhikari@aol.com

\begin{abstract}
The use of point-of-care (POC) ultrasonography has rapidly expanded in recent years, in both academic and community settings. It is one of the few diagnostic modalities that can be performed rapidly at the bedside by a physician and has significant impact on patient outcomes. It is portable, readily accessible, and cost-effective, and has no risk of ionizing radiation. There is an abundance of evidence that supports the use of POC ultrasound by physicians in different subspecialties. Multiple studies have documented the diagnostic accuracy of POC ultrasound and its ability to decrease the time to definitive treatment. As ultrasound technology has advanced, POC ultrasound applications have also evolved from being used solely in patients with blunt abdominal trauma to applications for nearly every clinical scenario imaginable. From performing procedures more safely to diagnosing pathology more quickly, POC ultrasound is radically changing clinical practice, patient outcomes, and the overall quality of patient care a clinician can provide. Recently, there has been a paradigm shift involving a symptom-based approach to POC ultrasound. This unique symptom-based ultrasound approach has led to improved quality of care in a variety of clinical settings.
\end{abstract}

Keywords: point-of-care ultrasound, ultrasonography, bedside ultrasound, emergency physician, emergency department, quality, symptom-based

\section{Introduction}

The use of ultrasound is widespread in emergency departments, inpatient units, and outpatient settings. Ultrasound services have been traditionally offered by radiology departments; however, in recent years, physicians in different specialties have adopted point-of-care (POC) ultrasound technology. POC ultrasound is primarily used to answer focused clinical questions at the bedside, narrow the differential diagnosis, and direct appropriate therapy. This practice has many advantages over traditional imaging modalities. It is rapid, portable, noninvasive, repeatable, less expensive, and does not carry the risk of ionizing radiation. Since it is performed at the bedside, it is ideal in the setting of an unstable patient. The use of POC ultrasound is now widespread in both community and academic settings. ${ }^{1}$

Clinician-performed ultrasound dates back to the early 1980s, when it was first utilized by German trauma surgeons for rapid evaluation of patients with blunt trauma. It resulted in a high degree of accuracy when compared with clinical outcomes at the time. The term "focused abdominal sonography in trauma" (FAST) was coined by Rozycki et al, who were early adopters of trauma ultrasound in North America. ${ }^{2}$ That now distant introduction of ultrasound in trauma heralded the progressive expansion of use of ultrasound by emergency physicians as well as tremendous diversification 
of its use. The scope of POC ultrasound practice has grown from a single application to include every organ system and virtually every disease process. The application of POC ultrasound in emergency medicine is rapidly expanding. ${ }^{3} \mathrm{Key}$ factors contributing to ongoing growth of POC ultrasound include access to improved ultrasound technology, advanced ultrasound education, acquisition of advanced skills, endorsement of POC ultrasound use by multiple societies, and the establishment of an overwhelming body of scientific medical literature supporting the use of ultrasound by emergency physicians. Ultrasound technology is rapidly evolving and ultrasound systems are becoming more compact, affordable, and easy to use, with ever improving image resolution. ${ }^{4}$ Multiple studies have shown that with appropriate training, emergency physicians can accurately perform and interpret bedside ultrasound examinations, the results of which they can incorporate into their clinical decision-making. ${ }^{3}$

Prior studies have shown that use of POC ultrasound by emergency physicians not only improves diagnostic accuracy but also decreases time to consultation and length of stay in the emergency department., 5 POC ultrasound has been shown to alter the management of critically ill patients in the emergency department, including those with pericardial effusion, pulmonary embolism, pneumothorax, and ectopic pregnancy. ${ }^{7-9}$ Additionally, the use of ultrasound for procedural guidance has been shown to be cost-effective, to decrease complication rates, and to improve patient safety. ${ }^{10}$ The unique advantages of POC ultrasound performed by clinicians include rapid assessment of critically ill patients presenting with a variety of symptoms, such as chest pain, shortness of breath, or undifferentiated hypotension. This paper discusses how POC ultrasound can be used to evaluate patients presenting with a variety of symptoms and how ultrasound improves quality of care in clinical practice.

\section{Shortness of breath}

Patients presenting to the emergency department with a chief complaint of dyspnea can be very challenging to the physician. The traditional approach to these patients includes a good history, physical examination, and a chest radiograph, and each component has significant limitations. An adequate history can be limited by confusion, anxiety, and respiratory distress. The physical examination can be limited by body habitus, ambient noise from a chaotic environment, and respiratory effort. The chest radiograph can be limiting because it relies on availability of a radiology technician, a portable machine that requires transport, and a radiologist to provide a final interpretation. Patients who complain of dyspnea benefit from the availability of POC ultrasound because: it can provide a faster and more accurate diagnosis; it can empower clinicians to provide the appropriate therapy more quickly; it can be repeated to demonstrate improvement of the disease process; and it is free of radiation.

As an example, a 60-year-old male with a history of chronic obstructive pulmonary disease presents to the emergency department complaining of dyspnea that has worsened over the past 3 weeks. The patient has a chronic history of cough but denies fevers. His past medical history is significant for coronary artery disease, with one coronary stent placed 2 years ago. He has no history of heart failure. His vital signs included a blood pressure of 120/80 $\mathrm{mmHg}$, heart rate 98 beats per minute, respiratory rate 24 per minute, temperature of $37.0^{\circ} \mathrm{C}$, and oxygen saturation $90 \%$ on room air. Physical examination reveals a visibly dyspneic obese male with diffusely diminished breath sounds. In addition, examination of his lower extremities reveals pitting edema. A chest radiograph is ordered and the patient is placed on supplemental oxygen.

At this point, bedside ultrasound can be incorporated into the assessment of this patient. Focused cardiac ultrasound reveals decreased cardiac contractility, and an evaluation of the inferior vena cava demonstrates a plethoric respiratory response (Figure 1). In addition, thoracic ultrasound is performed and demonstrates pathologic B-lines diffusely (Figure 2) with notable bilateral pleural effusions. There is normal pleural slide (Figure 3) and no evidence of lung consolidation. As a result of these POC ultrasound findings suggesting pulmonary edema, respiratory therapy is paged to administer positive pressure support; the patient is given $40 \mathrm{mg}$ of intravenous furosemide; and a bed request is made in the step down unit for new-onset congestive heart failure.

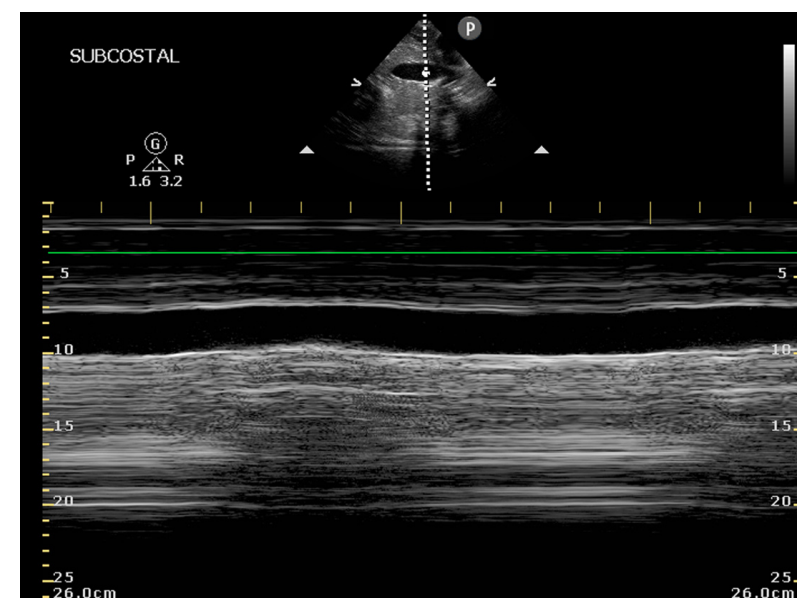

Figure I Plethoric inferior vena cava with loss of respiratory variation. 


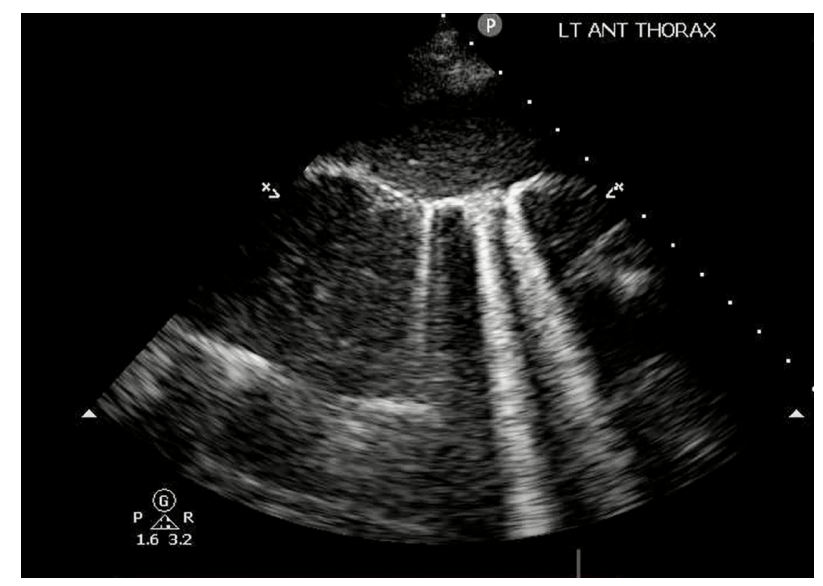

Figure 2 Lung rockets (B-lines extending from the pleural line to the edge of the screen) suggesting pulmonary edema.

Often this can be accomplished before the radiology technician comes to the bedside to perform the chest radiograph.

Thoracic ultrasound has been shown to be an excellent imaging modality for numerous thoracic disease processes. POC thoracic ultrasound is nearly $100 \%$ sensitive for the diagnosis of pneumothorax. ${ }^{11-13}$ In addition, one study found it to be equal to chest radiography for the detection of traumatic hemothorax, with a sensitivity and specificity of $96.2 \%$ and $100 \%$, respectively. ${ }^{14}$ Regarding pleural effusions, ultrasound is more accurate at quantifying how much fluid is present (20 mm effusion equates to approximately $400 \mathrm{~mL}) .{ }^{15}$ For diagnosis of interstitial disease such as pulmonary edema, POC ultrasound has been shown to be superior to chest radiography. ${ }^{16}$ Furthermore, one study demonstrated similar likelihood ratios when compared with pro-brain-type natriuretic peptide in the diagnosis of congestive heart failure. ${ }^{17}$ For the diagnosis of pneumonia, studies

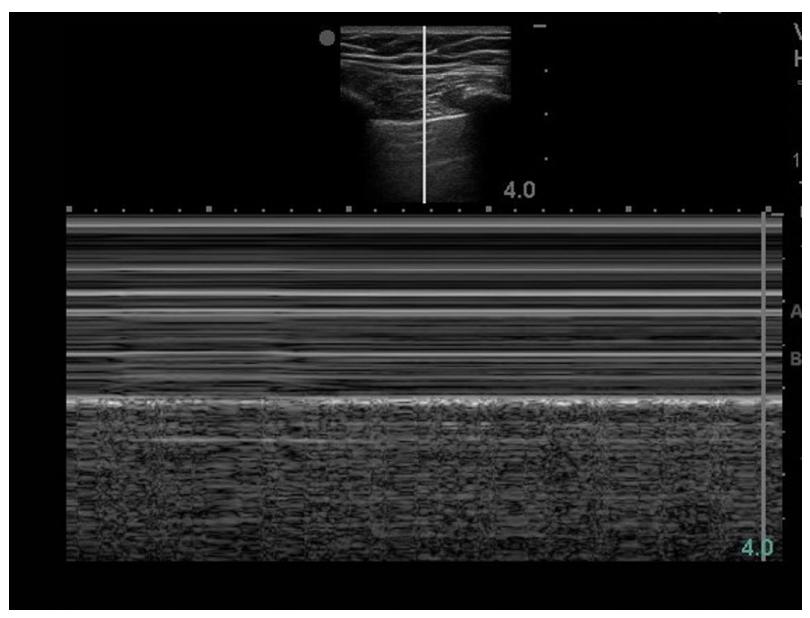

Figure 3 M-mode image demonstrating seashore sign seen with normal lung sliding. have indicated similarities to computed tomography (CT) and improvement over chest radiography. ${ }^{18-20}$

The application of POC ultrasound to the care of a patient with shortness of breath can improve clinical practice and patient care. In patients with complex clinical scenarios presenting with dyspnea, POC ultrasound can help differentiate between congestive heart failure, chronic obstructive pulmonary disease, pneumonia, and pneumothorax with great sensitivity and specificity.

\section{Chest pain (trauma)}

For patients presenting to the emergency department with chest and thoracic trauma, bedside ultrasonography is one of the most powerful tools available for the emergency physician. Focused evaluation of the pericardium for effusion in the setting of trauma is one of the principal elements of the FAST examination and has been shown to be highly accurate (sensitivity of $100 \%$ and specificity of $99.3 \%$ ). ${ }^{21}$ Additionally, this element of the FAST examination has been shown to decrease time to definitive management, and improve mortality and neurologic outcome in patients with penetrating cardiac injury. ${ }^{22}$

\section{Chest pain (nontrauma)}

Bedside ultrasonographic evaluation of emergency department patients presenting with nontraumatic chest pain aids in the diagnosis of several life-threatening illnesses. In patients with acute myocardial ischemia, use of POC echocardiography can potentially avoid delays in care and prevent adverse outcomes. Prior research demonstrated that regional wall motion abnormalities appear rapidly after the onset of severe ischemia from acute coronary occlusion, and these abnormalities can be detected on bedside cardiac ultrasound..$^{23}$ The ability of emergency physicians to detect regional wall motion abnormalities has recently been studied. ${ }^{24}$ Another clinical consideration in the emergency department patient with chest pain is pulmonary embolism. Pulmonary embolism is a challenging diagnosis despite the plethora of decision rules and possible imaging modalities. POC multiorgan sonography (cardiac, thoracic, and lower extremity venous sonography) for patients with suspected pulmonary embolism has a combined sensitivity and specificity of $90 \%$ and $86.2 \%$. In patients with a multiorgan sonographic examination negative for pulmonary embolism and a negative D-dimer, none were subsequently found to have pulmonary embolism. ${ }^{25}$ For patients too unstable for definitive diagnostic imaging, but at high risk for pulmonary embolism, POC ultrasonographic evidence of right heart dysfunction, 
in combination with clinical signs of obstructive shock, can be used to guide the decision to administer thrombolytics (Figure 4). ${ }^{26}$ In patients with chest pain, bedside ultrasound can also help with evaluation of the thoracic cavity to assess for pathology such as pneumothorax. In a study by Blaivas et al, ultrasound had a sensitivity of $98.1 \%$ and a specificity of $99.2 \%$ for the detection of pneumothorax as compared with chest radiography, which has a sensitivity of $75.5 \%$ and a specificity of $100 \%{ }^{27}$

\section{Shock}

Patients presenting to the emergency department with shock create a high-stakes situation for the treating physician, because they have high mortality and the differentials are broad. Rapid and early diagnosis of the underlying condition is paramount, but may be limited due to inability to obtain a complete history and physical examination or desired imaging due to the patient's high acuity of illness. POC ultrasonography, however, does not require transport of the patient and can be used to rule in or rule out a number of possible diagnoses rapidly. Several algorithms have been developed that utilize bedside ultrasonography of several organ systems to aid in rapid diagnosis and assist in early management of patients with undifferentiated hypotension. ${ }^{28-31}$ In general, these algorithms assess the heart for pericardial effusion, ejection fraction, right ventricular strain, and volume status, the lungs for pneumothorax and pulmonary edema, the abdomen for free fluid, the aorta for abdominal aortic aneurysm, and the lower extremities for deep vein thrombosis. Within minutes, critical information to distinguish different categories of shock is available and can be used to further guide therapy, choose additional diagnostic imaging, and for consultation. Obstructive shock resulting from massive pulmonary embolism or cardiac tamponade can be distinguished from hypovolemic or septic shock to direct appropriate fluid resuscitation. In a study by Atkinson et al, early multisystem POC ultrasound improved diagnostic accuracy of the treating physician in the first 15 minutes of patient presentation by $30 \% .^{28}$

Emergency medicine physicians can diagnose pericardial effusion on POC ultrasound with a specificity of $98 \%$ and a sensitivity of $96 \% .{ }^{32}$ The underlying incidence of pericardial effusion in emergency department patients with unexplained dyspnea and no known prior pericardial effusion is $14 \%$, suggesting that occult pericardial effusion is an important entity (Figure 5). ${ }^{33}$ As the history and physical examination are unreliable indicators of patients who may have pericardial effusion, POC cardiac ultrasound can be used to make the diagnosis, thus altering the care of these patients in the

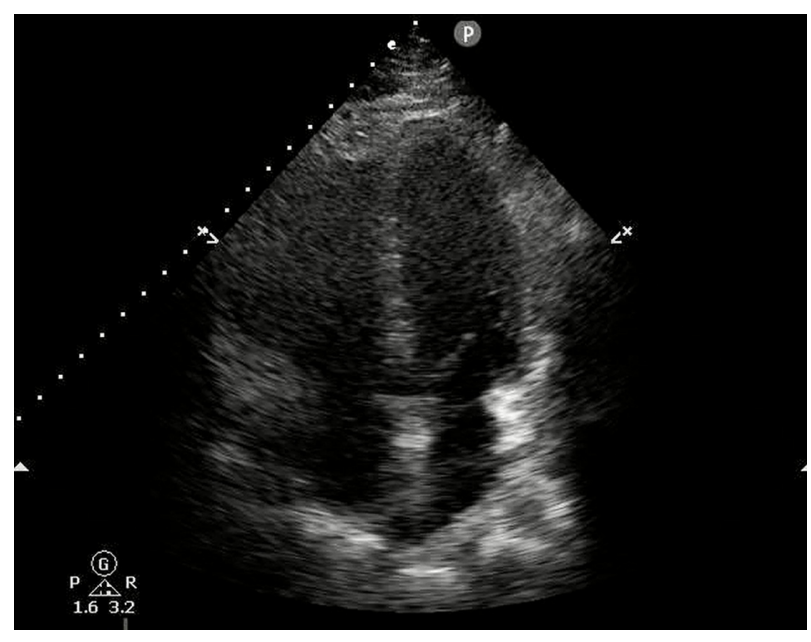

Figure 4 Apical 4 chamber axis view showing enlargement of the right ventricle in a patient with pulmonary embolism.

emergency department. When patients with pericardial effusion present with hemodynamic compromise and require pericardiocentesis, POC ultrasonography can have a significant impact on patient care. In patients requiring emergent pericardiocentesis, guidance by ultrasound improves success and decreases complications. ${ }^{34}$

Assessment of left ventricular ejection fraction (LVEF) can be accomplished rapidly and accurately using POC ultrasound. One study found $86.1 \%$ overall agreement in LVEF assessment between emergency physician-performed POC ultrasound and echocardiographer-performed, cardiologist-interpreted echocardiography. ${ }^{35}$ Similar agreement was found in another study of hypotensive patients. ${ }^{36}$ Identification of hyperdynamic LVEF in a patient with shock is strongly correlated with sepsis. POC ultrasonographic diagnosis of hyperdynamic LVEF is $94 \%$ specific for sepsis. ${ }^{37}$ However,

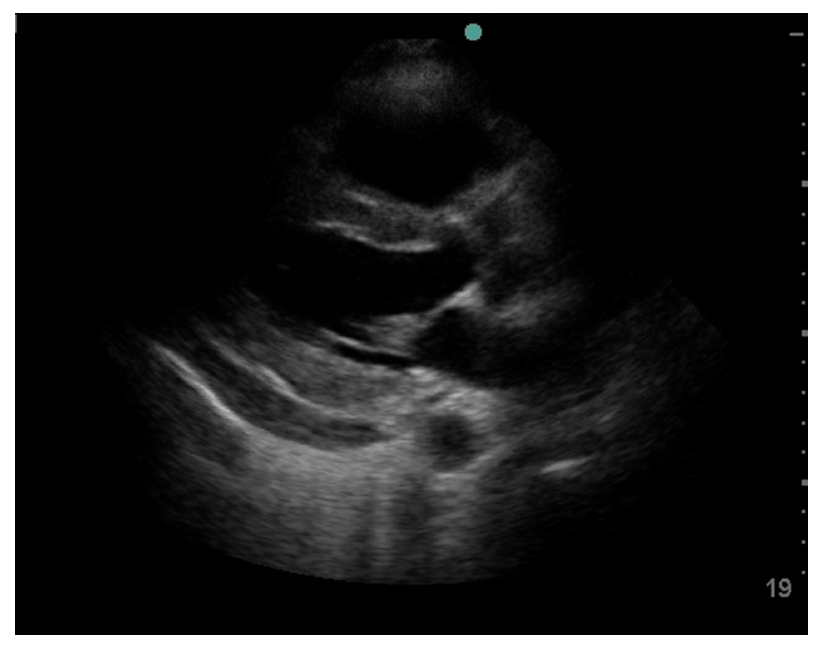

Figure 5 Parasternal long axis view showing pericardial effusion posterior to the left ventricle. 
severe sepsis can result in depressed myocardial contractility, and a hypodynamic left ventricle may be seen on ultrasound. A small-caliber inferior vena cava $(<2 \mathrm{~cm}$ diameter) with large inspiratory collapse and vigorous, hyperkinetic contractions obliterating the ventricle in systole has been shown to be correlated with hypovolemic shock. ${ }^{38}$

\section{Flank pain}

Use of CT to diagnose patients presenting to the emergency department with flank pain has risen dramatically over the last decade. Despite this increased use of radiation, accurate diagnosis of etiology of flank pain has not improved. ${ }^{39}$ This is detrimental to both patients due to ionizing radiation exposure and to the health care system due to cost. Despite the dramatic rise in the use of CT to diagnose renal colic, the rate of diagnosis of the disease has remained stable at $20 \%$. $^{39}$ Ultrasonography as the primary imaging modality for evaluation of patients with flank pain is superior to other modalities because it does not expose the patient to radiation.

POC renal ultrasonography can be used to accurately diagnose ureterolithiasis. The sensitivity of ultrasound for visualization of calculi in the ureter is low $(61 \%) .{ }^{40}$ However, POC renal ultrasonography is accurate in the detection of hydronephrosis (Figure 6). ${ }^{41}$ In selected patients with hematuria and hydronephrosis, the diagnosis of nephrolithiasis can be made with no further diagnostic testing. The overall sensitivity and specificity of POC ultrasound to detect ureterolithiasis in patients with suspected renal colic and hematuria are $87 \%$ and $84 \%$, respectively. ${ }^{42}$ The sensitivity of renal ultrasonography to detect any relevant clinical abnormality is $92 \% .{ }^{40}$ The main disadvantage of utilizing ultrasonography over CT in the evaluation of patients with flank pain is the

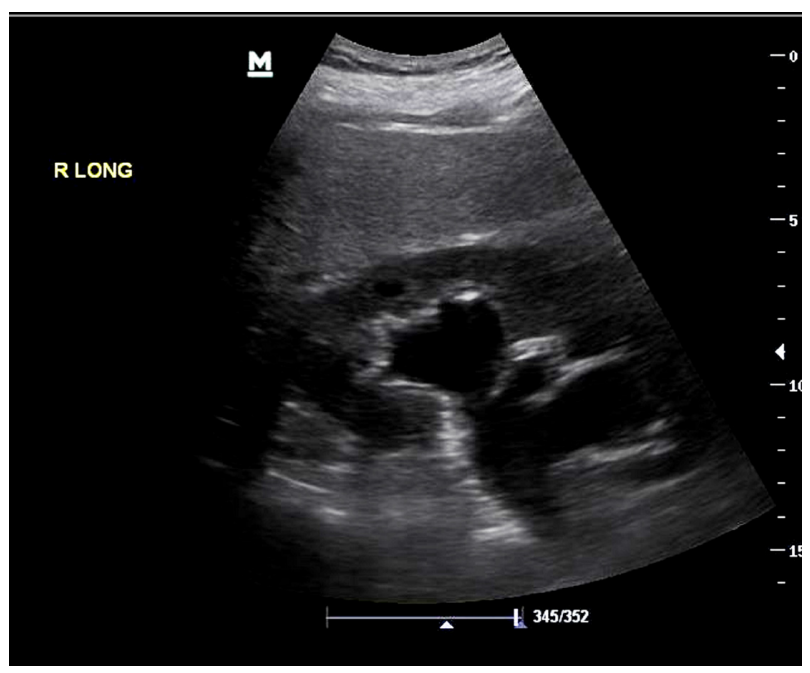

Figure 6 B-mode image of kidney with hydronephrosis and hydroureter. ability of CT to identify alternative diagnoses. This occurs in roughly $6 \%$ of patients with suspected uncomplicated renal colic. ${ }^{43}$ Missed appendicitis and ruptured abdominal aortic aneurysm are the key diagnoses that may mimic renal colic. These diagnoses can be investigated using POC ultrasound as well, and further examination of the patient may be warranted in the setting of a negative renal ultrasound.

Clinical algorithms that utilize ultrasonography first for diagnostic testing of patients presenting to the emergency department with flank pain have been proposed. ${ }^{44}$ When prospectively evaluated using POC ultrasound, these algorithms have performed well. More than $50 \%$ of patients presenting with acute flank pain can be safely discharged from the emergency department after only urinalysis and POC renal ultrasound examination. ${ }^{45}$ Other causes of flank pain that could be evaluated by POC ultrasound but have not been extensively studied include pyelonephritis, perinephric abscess, calyceal rupture, and renal trauma.

\section{Pelvic pain}

Ultrasonography is the main diagnostic modality used for evaluation of pelvic pain in the emergency department. Emergency medicine physicians have demonstrated accuracy and skill using POC pelvic ultrasonography for a variety of diagnoses. Time to diagnosis and length of stay in the emergency department is significantly decreased with the use of POC pelvic ultrasound. ${ }^{46}$

In pregnant patients presenting to the emergency department with pelvic pain, POC ultrasound can be used to rule out ectopic pregnancy. The proportion of ectopic pregnancies is higher among pregnant patients presenting to the emergency department than in the general pregnant population, therefore ruling out ectopic pregnancy is at the forefront of early symptomatic pregnancy evaluation. ${ }^{47-49}$ The sensitivity of emergency physician-performed POC pelvic ultrasound for the diagnosis of intrauterine pregnancy (Figure 7) is around $90 \%$, with a specificity of greater than $98 \% .{ }^{50}$ Historical and physical examination findings are unreliable in making the diagnosis, and the $\beta$-subunit of human chorionic gonadotropin should not be used to exclude the diagnosis of ectopic pregnancy. ${ }^{51,52}$ In the subset of patients with ectopic pregnancy (Figure 8), POC ultrasound has a sensitivity of $99.3 \%$ in identifying the absence of an intrauterine pregnancy, with a negative predictive value of $99.6 \% .^{53}$ Additionally, the management of patients with ruptured ectopic pregnancy (Figure 9) is improved with the use of POC ultrasound. Positive abdominal free fluid in Morrison's pouch (Figure 10) in patients with suspected ectopic pregnancy predicts a need 


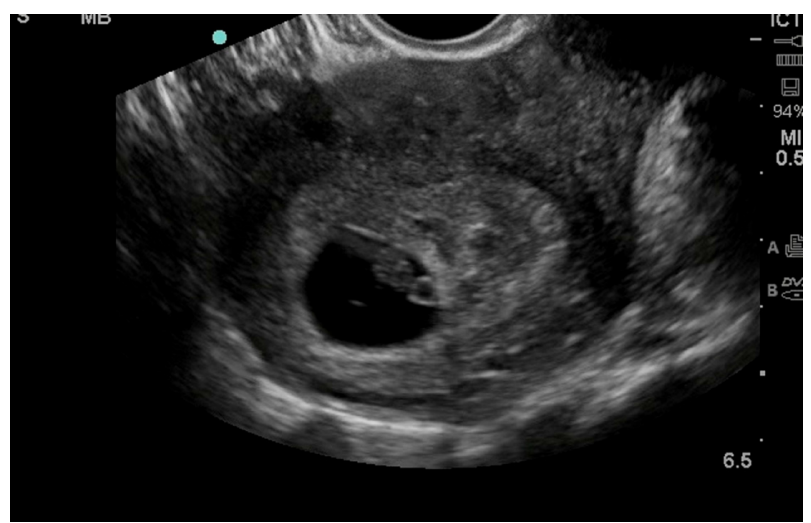

Figure $\mathbf{7}$ Intrauterine pregnancy with yolk sac and fetal pole.

for operative intervention..$^{54}$ Using POC ultrasound to assess for abdominal free fluid when evaluating these patients has been shown to decrease time to operative management. ${ }^{55}$ Other first-trimester pregnancy complications that may present with pelvic pain, such as fetal demise, nonviable pregnancy, and subchorionic hemorrhage, can also be evaluated by POC ultrasound (Figures 11 and 12).

In the second-trimester patient, POC sonography can assist with early detection of a shortened cervix and risk of preterm birth. The risk of spontaneous preterm labor is inversely associated with the length of the cervix, and is highest before 24 weeks' gestational age. A cervical length $\geq 30 \mathrm{~mm}$ has been shown to reliably exclude the diagnosis of preterm labor. ${ }^{56-58}$ In the third-trimester patient presenting with pelvic pain, POC ultrasound can be instrumental in establishing gestational age, presentation, and location of the placenta. Emergency physician accuracy in determining viability (gestational age $>24$ weeks) using POC ultrasound to measure biparietal diameter and femur length is $96 \%$ and the examination takes less than one minute. ${ }^{59} \mathrm{In}$ postpartum patients with pelvic pain, sonographic findings

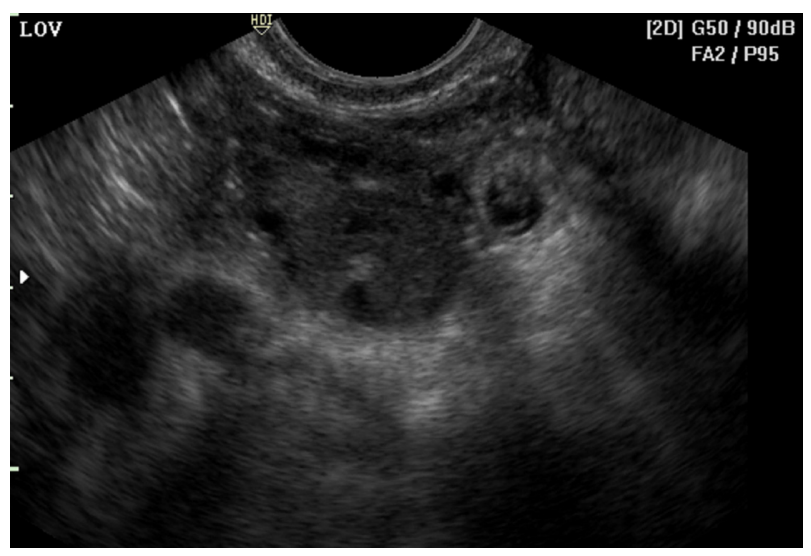

Figure 8 Ectopic pregnancy (left adnexal mass adjacent to ovary).

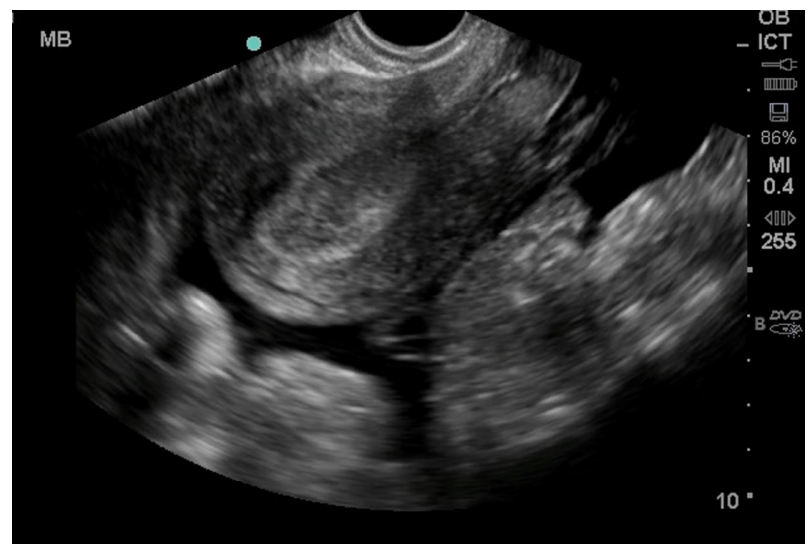

Figure 9 Ruptured ectopic pregnancy with empty uterus and large amount of free fluid in pelvis.

such as thickened, heterogeneous endometrium and intracavitary fluid collection are helpful in diagnosing endometritis. ${ }^{60}$ POC ultrasound can also assist in the rapid diagnosis of retained products of conception in patients with postpartum bleeding. The presence of a solid echogenic mass in the lumen or uterine wall on ultrasound examination is highly predictive of retained placenta (Figure 13) ${ }^{61}$

The utility of POC pelvic ultrasound in the evaluation of pelvic pain in nonpregnant patients presenting to the emergency department has been investigated. ${ }^{62}$ The major differential diagnoses in these patients include ovarian torsion, ruptured hemorrhagic ovarian cyst, and tubo-ovarian abscess. The detection of a markedly enlarged ovary with multiple follicles along the periphery of the engorged ovary or abnormal ovarian blood flow on POC ultrasound can expedite gynecologic consultation for possible ovarian torsion. ${ }^{63}$ The presence of pyosalpinx, or a complex adnexal mass with septations, irregular margins and destruction of the normal ovarian and fallopian tube architecture, or loculated, speckled, echogenic fluid in the cul-de-sac are highly

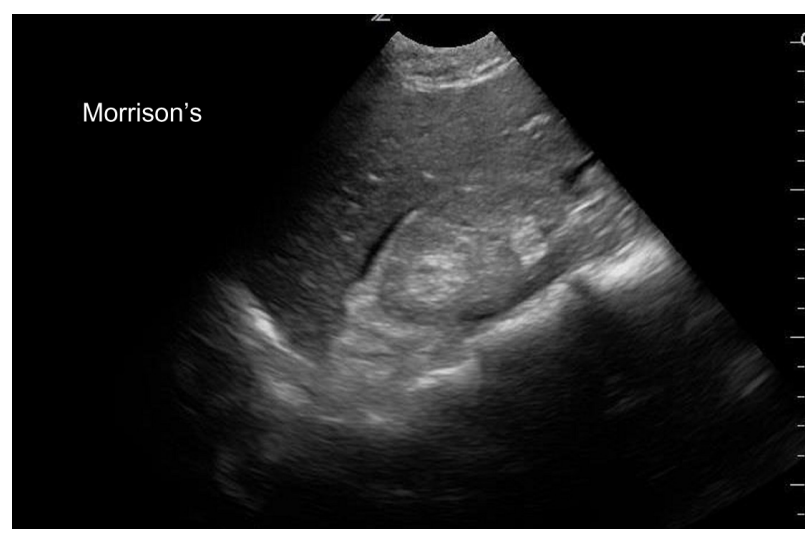

Figure 10 Fluid in Morrison's pouch from ruptured ectopic pregnancy. 


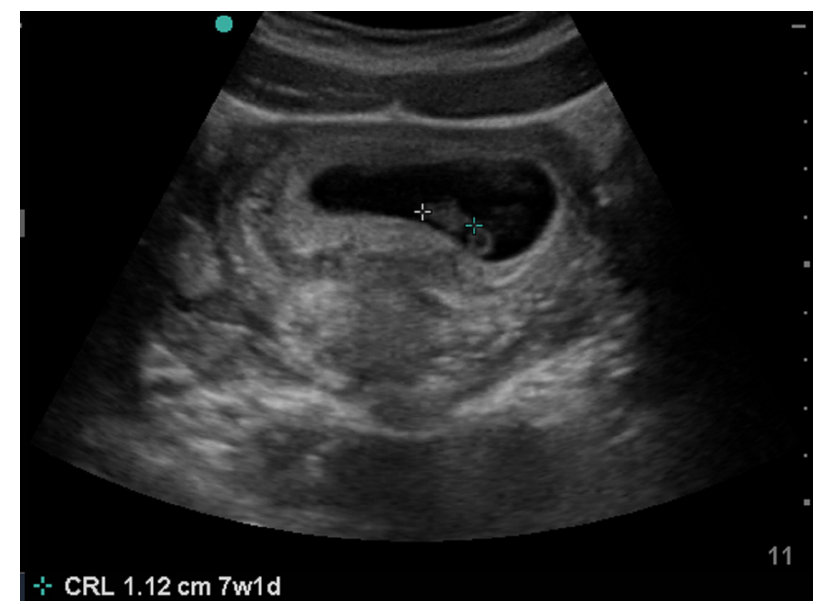

Figure II Intrauterine pregnancy with fetal pole $>7 \mathrm{~mm}$ and no cardiac activity suggesting nonviable pregnancy.

suggestive of tubo-ovarian abscess and require admission, intravenous antibiotics, and a gynecologic consultation (Figure 14). ${ }^{62}$ Hemorrhagic cysts can rupture and cause massive hemoperitoneum, leading to hemorrhagic shock and hemodynamic instability requiring operative intervention (Figure 15). Early diagnosis of cyst rupture using POC ultrasound can potentially expedite the time to operative intervention.

\section{Ocular pain and visual disturbances}

Patients presenting to the emergency department with a chief complaint of visual disturbances or ocular pain often require consultation. The challenge the clinician must decide is how soon to demand the consultation. The traditional approach to these patients includes a good history, slit-lamp examination, and optic nerve evaluation, and each has its own limitations. The historical details of different ocular pathologies are often similar. The slit-lamp examination is unable to extend beyond

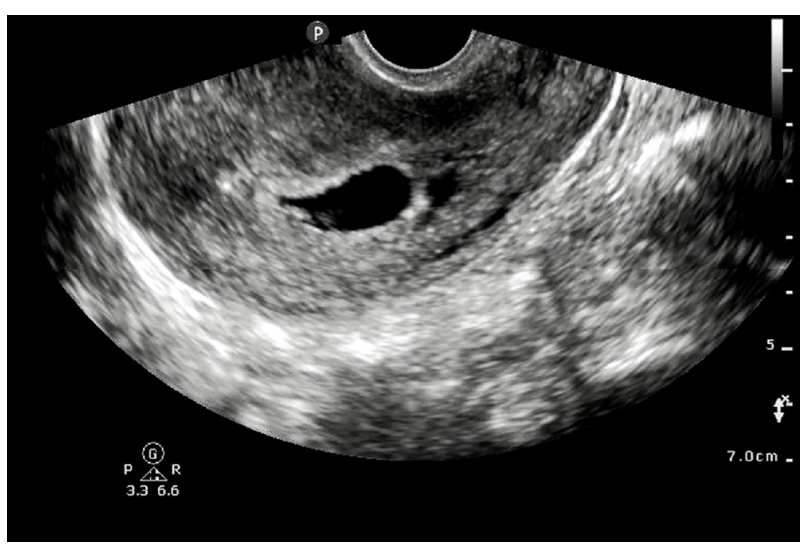

Figure 12 Subchorionic hemorrhage (anechoic collection) adjacent to gestational sac.

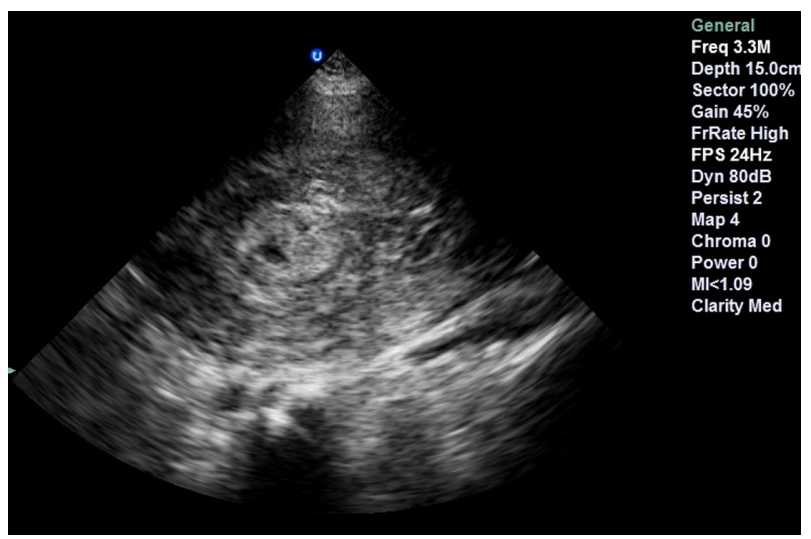

Figure 13 Echogenic endometrial mass suggesting retained placenta in a patient with postpartum bleeding who required operative intervention.

the lens. Emergency physicians often do not use mydriatics to facilitate ocular examinations. Patients who complain of visual disturbances benefit from the availability of POC ultrasound because: it can provide a faster and more accurate diagnosis; it can empower clinicians to obtain consultation more quickly; and it can provide the consultant information with which to make definitive management plans such as laser surgery.

As an example, a 70-year-old male with a history of diabetes presents to the emergency department complaining of sudden loss of vision in the inferior aspect of his left eye. The patient has a history of cataracts but has had surgery done with insertion of an intraocular lens in both eyes. His vital signs include a blood pressure of 120/80 $\mathrm{mmHg}$, heart rate 80 beats per minute, respiratory rate 18 per minute, temperature $37.0^{\circ} \mathrm{C}$, and oxygen saturation $100 \%$ on room air. Visual acuity is 20/100 in the left eye, 20/40 in the right eye, and 20/60 with bilateral eye use. Ocular pressures are $18 \mathrm{mmHg}$ bilaterally. Visual field testing demonstrates complete deficit

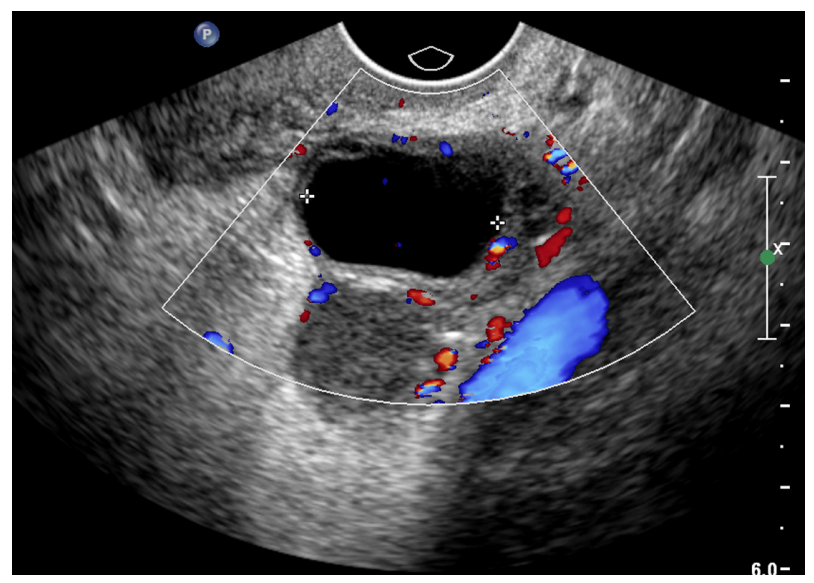

Figure 14 Tubo-ovarian abscess. 


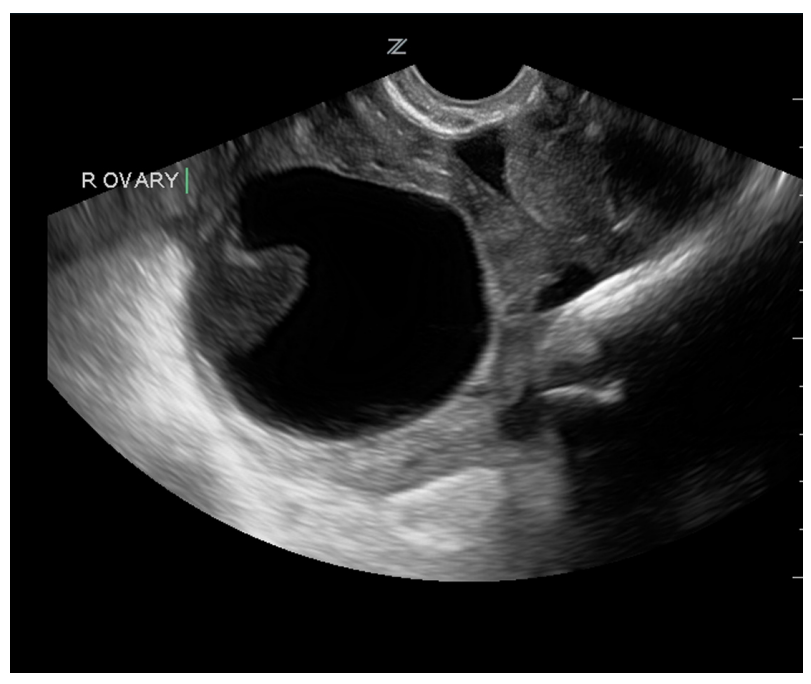

Figure $\mathbf{5}$ Hemorrhagic ovarian cyst with retracting clot.

of the left inferior medial field. Slit-lamp examination demonstrates normal lids/lashes, the anterior chamber is quiet without flair or cells, the iris is $2+$ and reactive, and the lens is clear. Ophthalmoscopic examination is difficult with the intraocular lens reflection.

At this point, bedside ultrasound can be incorporated into the assessment of this patient. Focused ocular ultrasound reveals normal lens location (Figure 16), retinal detachment tethered at the optic nerve (Figure 17), and an optic nerve assessment demonstrating a normal diameter (Figure 18). As a result of this POC ultrasound, ophthalmology is consulted, and a diagnosis of "mac-on" retinal detachment is conveyed.

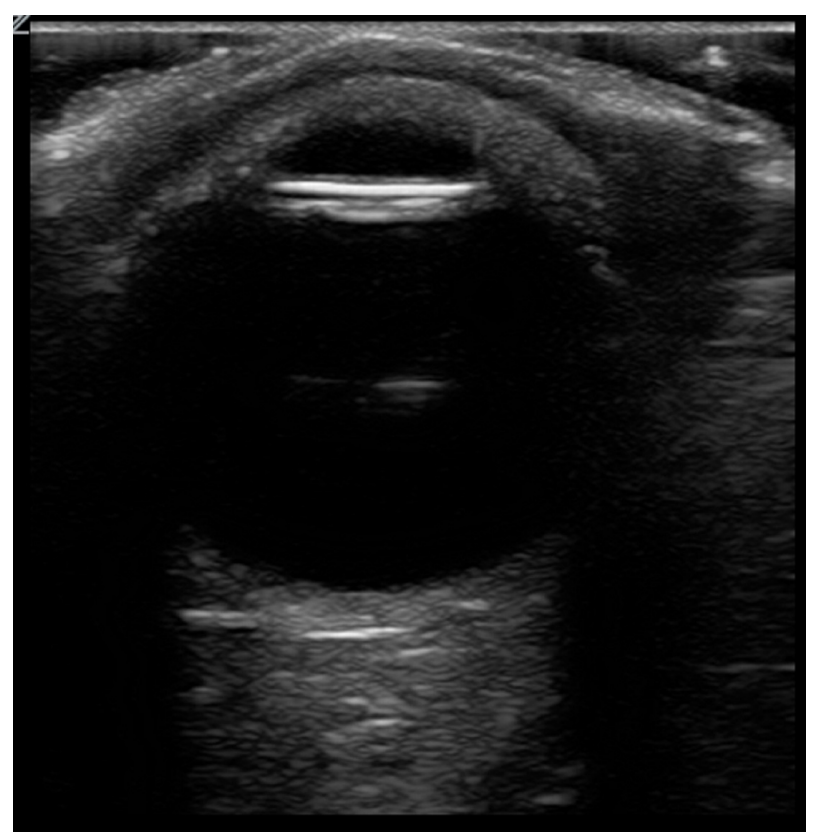

Figure 16 Normal lens location.

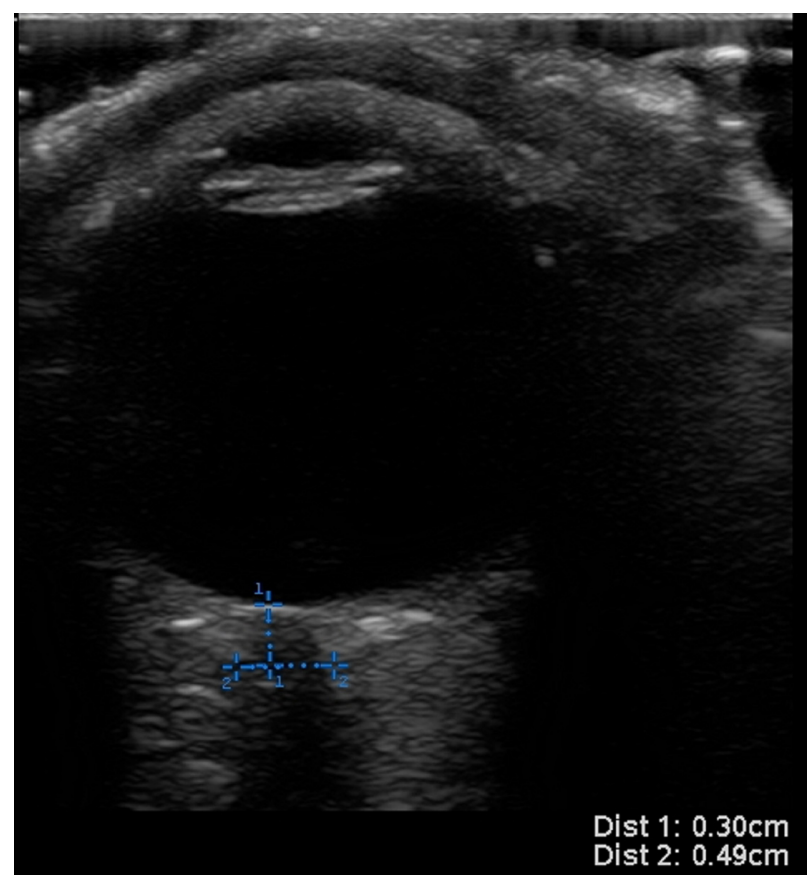

Figure 17 Normal optic nerve sheath diameter.

Due to this finding, ophthalmology prepares the operating room for possible laser surgery.

Ocular ultrasound has been shown to be useful to the emergency physician for the diagnosis of numerous ocular pathologies. POC ultrasound for the detection of foreign body in the eye has a positive predictive value of $96.5 \% .{ }^{64}$ Although difficult to see with direct funduscopy, ultrasound has a sensitivity and specificity of $97 \%$ and $93 \%$, respectively, for the

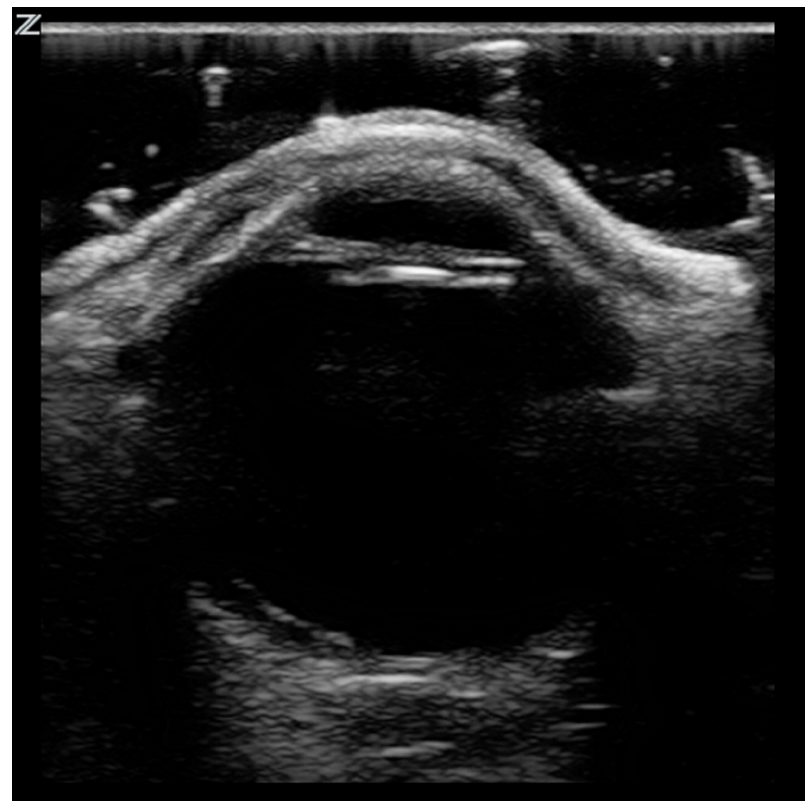

Figure 18 Retinal detachment tethered at the optic nerve. 
detection of retinal detachments. ${ }^{65}$ Finally, ocular ultrasound can detect elevated intracranial pressure $(>20 \mathrm{mmHg})$ with a sensitivity and specificity of $90 \%$ and $85 \%$, respectively (Figure 19). ${ }^{66,67}$

As demonstrated above, application of POC ultrasound in the care of a patient with vision loss improves clinical practice and patient care. POC ultrasound can help identify retinal detachment involving the macula, retinal detachment with macula sparing, vitreous detachment, vitreous bleed, lens dislocation, globe rupture, iritis, hyphema, and many more diagnoses. In addition, POC ultrasound can decrease the time to consultation and disposition.

\section{Joint pain}

Emergency physicians frequently evaluate patients with joint pain, redness, and swelling. The causes of a swollen painful joint include cellulitis, abscesses, hematoma, arthritis, hemarthrosis, and bursitis. Appropriate evaluation and treatment can help prevent complications and improve patient outcomes. However, the diagnosis of a swollen painful joint is not always clear clinically since signs and symptoms are neither sensitive nor specific for identifying a joint effusion. ${ }^{68,69}$ Additionally, physical examination can be limited by pain, soft tissue swelling, and patient compliance. Traditionally, emergency physicians have performed a diagnostic joint aspiration to rule out a joint effusion. With this approach, patients with isolated soft tissue abnormalities are subjected to unnecessary blindly performed invasive procedures even though they do not have a joint effusion.

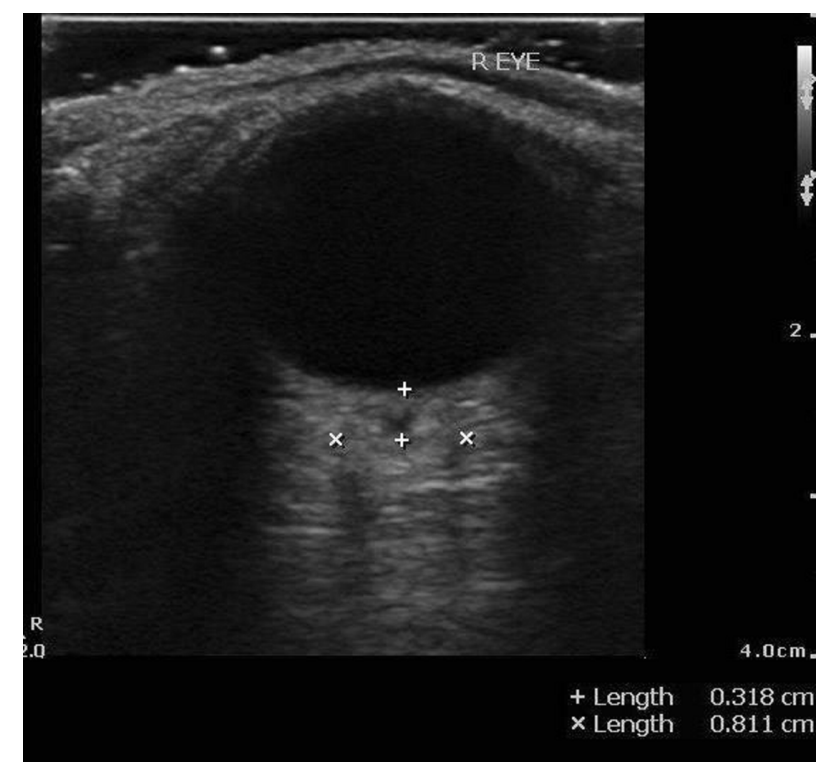

Figure 19 Abnormal optic nerve sheath diameter suggesting increased intracranial pressure.
In addition, it is difficult to aspirate small joint effusions with the blind technique, leading to multiple attempts and potentially misdiagnosis.

Musculoskeletal ultrasound is a rapid and sensitive technique for detecting the presence of joint effusions (Figures 20 and 21) and can assist physicians to decide whether an aspiration needs to be done, whether to request additional diagnostic imaging and consultation, or whether to manage with other conservative measures. ${ }^{70,71}$ The superiority of ultrasound over radiography in identifying a joint effusion has been well studied. ${ }^{72,73}$ In a study done by Adhikari et al in the emergency department, POC musculoskeletal sonography altered the treatment of patients presenting with joint symptoms significantly. More than $50 \%$ of futile joint aspirations were avoided in their study population based on POC ultrasound findings. ${ }^{74}$ Additionally, POC musculoskeletal sonography detected joint effusions in approximately $50 \%$ of patients in whom aspiration was not planned by the treating emergency physicians, which resulted in accurate diagnosis, appropriate consultation, and therapy. The use of POC ultrasound-guided arthrocentesis (Figure 22) has also been shown to increase operator confidence and decrease the procedure time and pain experienced by the patient during the procedure. ${ }^{75}$

\section{Procedures}

Patients often present to the emergency department with complaints that will ultimately require a procedure. Whether the procedure is an incision and drainage or fluid aspiration, the traditional approach often involves anatomic landmarkguided techniques. The limitations to landmark-guided techniques include patient body habitus, severity of disease,

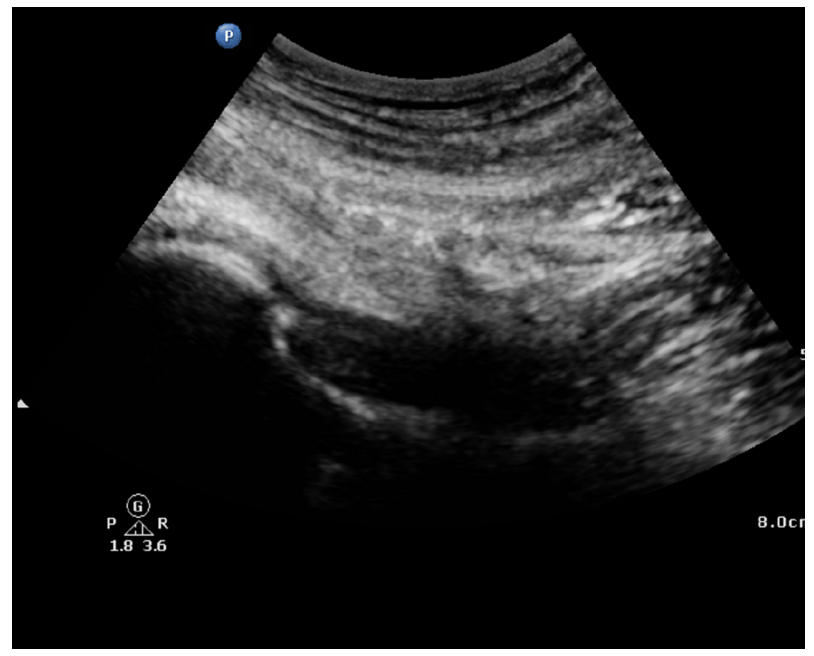

Figure 20 Hip effusion. Capsular distension with anechoic fluid. 


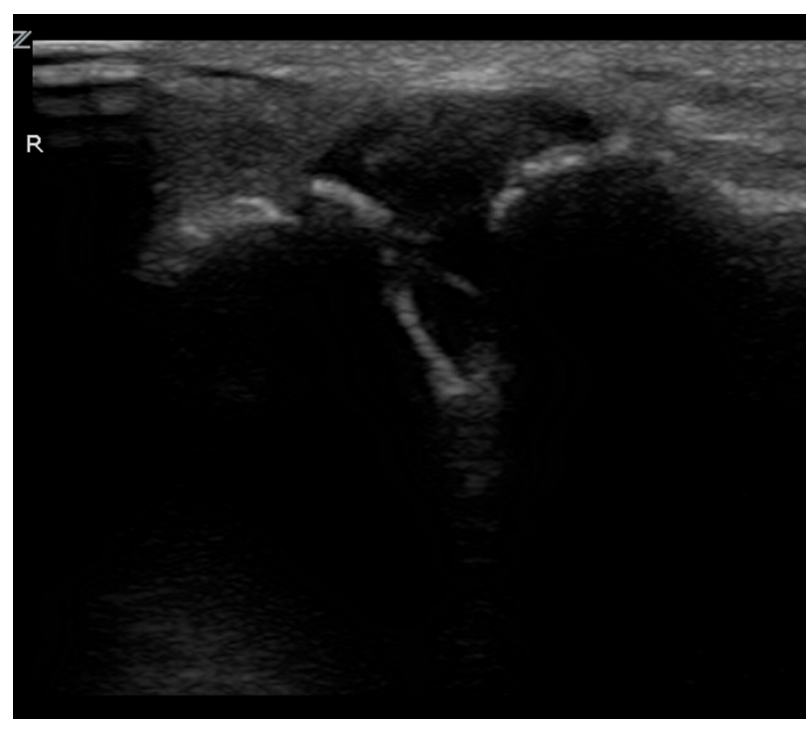

Figure 2 I Acromioclavicular joint effusion in an immunocompromised patient.

or quantity of fluid, as well as the experience and skill level of the clinician. Patients who will require procedures in the emergency department can benefit from the use of real-time ultrasound guidance because this has shown to increase operator confidence, and decrease the number of attempts, complication rates, and amount of anesthetic used.

The application of POC ultrasound in the care of patients who require emergent procedures improves clinical practice and patient care by providing a faster diagnosis and immediate feedback essential when performing a procedure. The ultrasound-guided technique most often used is needle guidance for vascular access. It has been shown that the use of ultrasound can increase success rates, decrease complications, and improve patient satisfaction in patients requiring

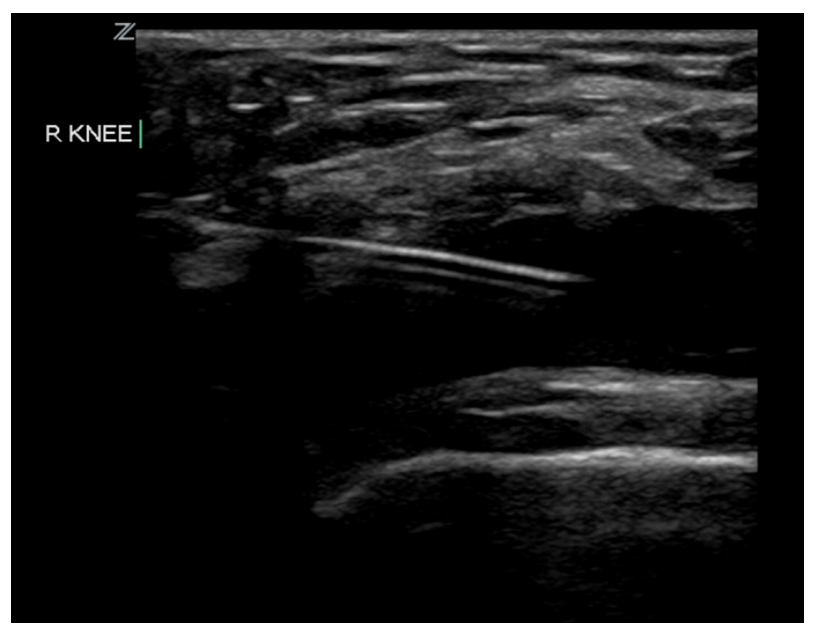

Figure 22 Real-time ultrasound guidance used to perform knee arthrocentesis. Note: Needle tip seen in the image.

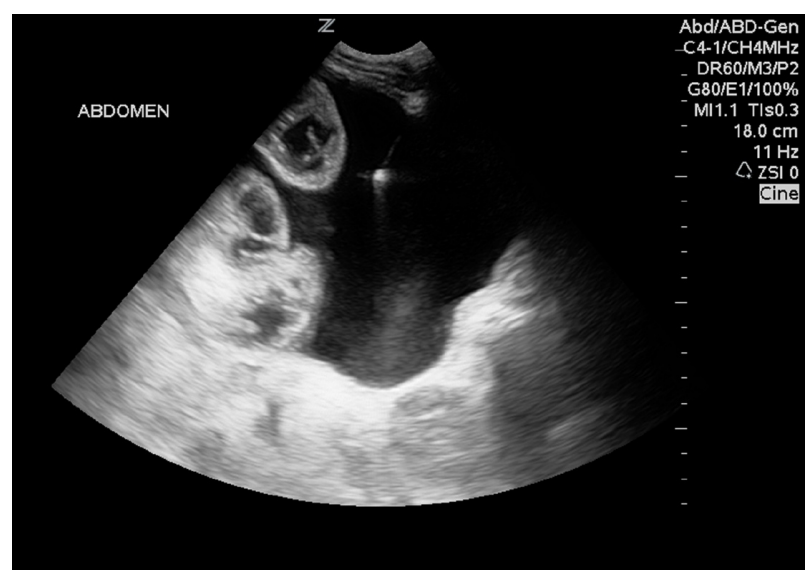

Figure 23 Ultrasound-guided paracentesis.

Note: Needle tip seen in ascitic fluid adjacent to bowel loops.

peripheral or central venous access. ${ }^{76,77}$ Ultrasound guidance for other procedures, such as paracentesis, thoracentesis, and pericardiocentesis, has been investigated. When performing a paracentesis, ultrasound can reduce the number of failed attempts by identifying which patients have little or no fluid present, and has been shown to increase success rates when compared with anatomic landmark techniques (95\% versus 65\%; Figure 23). ${ }^{78}$

Furthermore, studies have shown a smaller number of adverse events when ultrasound guidance was used for paracentesis (1.4\% versus $4.7 \%) .{ }^{79}$ With the incorporation of ultrasound guidance to perform thoracentesis, one study found that the incidence of pneumothorax decreased to $0 \% .{ }^{80}$ Ultrasound-assisted pericardiocentesis has also proven to be an effective procedure with a success rate of $97 \% .{ }^{34}$ As a result, ultrasound-guided techniques, which use real-time ultrasound guidance to direct needle placement, are replacing the anatomic landmark approach as the new standard for procedures.

\section{Conclusion}

POC ultrasound has been a unique addition to the practice of clinical medicine. At least every bit as revolutionary as the stethoscope, introduced in the 1800 s, its impact on our practice is orders of magnitude greater for both physicians and patients. Few potentially hand-held or at least highly portable devices have allowed the clinician to expand their capabilities so significantly in evaluating, diagnosing, and treating patients. The end of the age of blind, landmark-inserted central lines and other similar invasive procedures means decreased morbidity and mortality for our patients, with a concomitant increase in efficiency and practice satisfaction for clinicians. The ability to visualize the heart of an unstable, 
hypotensive patient or evaluate the lungs for pneumothorax or pulmonary edema without turning away from the patient, who is reliant on our skills to save them, cannot be underestimated. The efficiency, accuracy, and capability of our practice has changed forever. The ultimate beneficiaries will not just be the patient and society, but also the ultrasound-wielding clinician who can perform assessments and interventions at the bedside that were only dreamed of by clinicians in the ages prior to POC ultrasound.

\section{Disclosure}

The authors report no conflicts of interest in this work.

\section{References}

1. Bahner DP, Adkins EJ, Hughes D, Barrie M, Boulger CT, Royall NA. Integrated medical school ultrasound: development of an ultrasound vertical curriculum. Crit Ultrasound J. 2013;5(1):6.

2. Rozycki GS. Abdominal ultrasonography in trauma. Surg Clin North Am. 1995;75(2):175-191.

3. American College of Emergency Physicians. Emergency ultrasound guidelines. Ann Emerg Med. 2009;53(4):550-570.

4. Ault MJ, Rosen BT. Portable ultrasound: the next generation arrives. Crit Ultrasound J. 2010;2(1):39-42.

5. Thamburaj R, Sivitz A. Does the use of bedside pelvic ultrasound decrease length of stay in the emergency department? Pediatr Emerg Care. 2013;29(1):67-70.

6. Tayal VS, Hasan N, Norton HJ, Tomaszewski CA. The effect of soft-tissue ultrasound on the management of cellulitis in the emergency department. Acad Emerg Med. 2006;13(4):384-388.

7. Blyth L, Atkinson P, Gadd K, Lang E. Bedside focused echocardiography as predictor of survival in cardiac arrest patients: a systematic review. Acad Emerg Med. 2012;19(10):1119-1126.

8. Borloz MP, Frohna WJ, Phillips CA, Antonis MS. Emergency department focused bedside echocardiography in massive pulmonary embolism. J Emerg Med. 2011;41(6):658-660.

9. Adhikari S, Blaivas M, Lyon M. Diagnosis and management of ectopic pregnancy using bedside transvaginal ultrasonography in the ED: a 2-year experience. Am J Emerg Med. 2007;25(6):591-596.

10. Mercaldi CJ, Lanes SF. Ultrasound guidance decreases complications and improves the cost of care among patients undergoing thoracentesis and paracentesis. Chest. 2013;143(2):532-538.

11. Rowan KR, Kirkpatrick AW, Liu D, Forkheim KE, Mayo JR, Nicolaou S. Traumatic pneumothorax detection with thoracic ultrasound: correlation with chest radiography and $\mathrm{CT}$ - initial experience. Radiology. 2002;225(1):210-214.

12. Alrajab S, Youssef AM, Akkus NI, Caldito G. Pleural ultrasonography versus chest radiography for the diagnosis of pneumothorax: review of the literature and meta-analysis. Crit Care. 2013;23: 17(5):R208.

13. Zhang M, Liu ZH, Yang JX, Gan JX, Xu SW. Rapid detection of pneumothorax by ultrasonography in patients with multiple trauma. Crit Care. 2006;10(4):R112.

14. Ma OJ, Mateer JR. Trauma ultrasound examination versus chest radiography in the detection of hemothorax. Ann Emerg Med. 1997;29(3):312-315.

15. Eibenberger KL, Dock WI, Ammann ME, Dorffner R, Hormann MF, Grabenwoger F. Quantification of pleural effusions: sonography versus radiography. Radiology. 1994;191(3):681-684.

16. Zanobetti M, Poggioni C, Pini R. Can chest ultrasonography replace standard chest radiography for evaluation of acute dyspnea in the ED? Chest. 2011;139(5):1140-1147.
17. Liteplo AS, Marill KA, Villen T, et al. Emergency thoracic ultrasound in the differentiation of shortness of breath: sonographic B-lines and $\mathrm{N}$-terminal pro-brain type natriuretic peptide in diagnosing congestive heart failure. Acad Emerg Med. 2009;16(3):201-210.

18. Reissig A, Kroegel C. Sonographic diagnosis and follow-up of pneumonia: a prospective study. Respiration. 2007;74(5):537-547.

19. Cortellaro F, Colombo S, Coen D, Duca P. Lung ultrasound is an accurate diagnostic tool for the diagnosis of pneumonia in the emergency department. Emerg Med J. 2012;29(1):19-23.

20. Parlamento S, Copetti R, Di Bartolomeo S. Evaluation of lung ultrasound for the diagnosis of pneumonia in the ED. Am J Emerg Med. 2009;27(4):379-384.

21. Rozycki GS, Ballard RB, Feliciano DV, Schmidt JA, Pennington SD. Surgeon-performed ultrasound for the assessment of truncal injuries: lessons learned from 1540 patients. Ann Surg. 1998;228(4): 557-567.

22. Plummer D, Brunette D, Asinger R, Ruiz E. Emergency department echocardiography improves outcome in penetrating cardiac injury. Ann Emerg Med. 1992;21(6):709-712.

23. Weston P, Alexander JH, Patel MR, Maynard C, Crawford L, Wagner GS. Hand-held echocardiographic examination of patients with symptoms of acute coronary syndromes in the emergency department: the 30-day outcome associated with normal left ventricular wall motion. Am Heart J. 2004;148(6):1096-1101.

24. Adhikari S, Fiorello A, Stolz L, et al. Ability of emergency physicians with advanced echocardiographic experience at a single center to identify complex echocardiographic abnormalities. Am J Emerg Med. 2014;32(4):363-366.

25. Nazerian P, Vanni S, Volpicelli G, et al. Accuracy of point-of-care multiorgan ultrasonography for the diagnosis of pulmonary embolism. Chest. 2014;145(5):950-957.

26. American College of Emergency Physicians Policies Committee; Clinical Policies Committee Subcommittee on Suspected Pulmonary Embolism. Clinical policy: critical issues in the evaluation and management of adult patients presenting with suspected pulmonary embolism. Ann Emerg Med. 2003;41(2):257-270.

27. Blaivas M, Lyon M, Duggal S. A prospective comparison of supine chest radiography and bedside ultrasound for the diagnosis of traumatic pneumothorax. Acad Emerg Med. 2005;12(9):844-849.

28. Atkinson PR, McAuley DJ, Kendall RJ, et al. Abdominal and Cardiac Evaluation with Sonography in Shock (ACES): an approach by emergency physicians for the use of ultrasound in patients with undifferentiated hypotension. Emerg Med J. 2009;26(2):87-91.

29. Jones AE, Tayal VS, Sullivan DM, Kline JA. Randomized, controlled trial of immediate versus delayed goal-directed ultrasound to identify the cause of nontraumatic hypotension in emergency department patients. Crit Care Med. 2004;32(8):1703-1708.

30. Perera P, Mailhot T, Riley D, Mandavia D. The RUSH exam: Rapid Ultrasound in SHock in the evaluation of the critically ill. Emerg Med Clin North Am. 2010;28(1):29-56.

31. Rose JS, Bair AE, Mandavia D, Kinser DJ. The UHP ultrasound protocol: a novel ultrasound approach to the empiric evaluation of the undifferentiated hypotensive patient. Am J Emerg Med. 2001;19(4):299-302.

32. Mandavia DP, Hoffner RJ, Mahaney K, Henderson SO. Bedside echocardiography by emergency physicians. Ann Emerg Med. 2001;38(4):377-382.

33. Blaivas M. Incidence of pericardial effusion in patients presenting to the emergency department with unexplained dyspnea. Acad Emerg Med. 2001;8(12):1143-1146.

34. Tsang TS, Enriquez-Sarano M, Freeman WK, et al. Consecutive 1127 therapeutic echocardiographically guided pericardiocenteses: clinical profile, practice patterns, and outcomes spanning 21 years. Mayo Clin Proc. 2002;77(5):429-436.

35. Randazzo MR, Snoey ER, Levitt MA, Binder K. Accuracy of emergency physician assessment of left ventricular ejection fraction and central venous pressure using echocardiography. Acad Emerg Med. 2003;10(9):973-977. 
36. Moore CL, Rose GA, Tayal VS, Sullivan DM, Arrowood JA, Kline JA. Determination of left ventricular function by emergency physician echocardiography of hypotensive patients. Acad Emerg Med. 2002;9(3):186-193.

37. Jones AE, Craddock PA, Tayal VS, Kline JA. Diagnostic accuracy of left ventricular function for identifying sepsis among emergency department patients with nontraumatic symptomatic undifferentiated hypotension. Shock. 2005;24(6):513-517.

38. Seif D, Mailhot T, Perera P, Mandavia D. Caval sonography in shock a noninvasive method for evaluating intravascular volume in critically ill patients. J Ultrasound Med. 2012;31(12):1885-1890.

39. Hyams ES, Korley FK, Pham JC, Matlaga BR. Trends in imaging use during the emergency department evaluation of flank pain. $J$ Urol. 2011;186(6):2270-2274.

40. Sheafor DH, Hertzberg BS, Freed KS, et al. Nonenhanced helical CT and US in the emergency evaluation of patients with renal colic: prospective comparison. Radiology. 2000;217(3):792-797.

41. Jang TB, Casey RJ, Dyne P, Kaji A. The learning curve of resident physicians using emergency ultrasonography for obstructive uropathy. Acad Emerg Med. 2010;17(9):1024-1027.

42. Gaspari RJ, Horst K. Emergency ultrasound and urinalysis in the evaluation of flank pain. Acad Emerg Med. 2005;12(12):1180-1184.

43. Pernet J, Abergel S, Parra J, et al. Prevalence of alternative diagnoses in patients with suspected uncomplicated renal colic undergoing computed tomography: a prospective study. CJEM. 2014;16:1-7.

44. Swadron S. Renal ultrasound. In: Ma O, Mateer J, Blaivas M, editors. Emergency Ultrasound. 2nd ed. New York, NY, USA: McGraw Hill Professional; 2008.

45. Kartal M, Eray O, Erdogru T, Yilmaz S. Prospective validation of a current algorithm including bedside US performed by emergency physicians for patients with acute flank pain suspected for renal colic. Emerg Med J. 2006;23(5):341-344.

46. Shih $\mathrm{CH}$. Effect of emergency physician-performed pelvic sonography on length of stay in the emergency department. Ann Emerg Med. 1997;29(3):348-345.

47. [No authors listed]. From the Centers for Disease Control and Prevention. Ectopic pregnancy - United States, 1990-1992. JAMA. 1995;273(7):533.

48. Kaplan BC, Dart RG, Moskos M, et al. Ectopic pregnancy: prospective study with improved diagnostic accuracy. Ann Emerg Med. 1996;28(1):10-17.

49. Kohn MA, Kerr K, Malkevich D, O’Neil N, Kerr MJ, Kaplan BC. Beta-human chorionic gonadotropin levels and the likelihood of ectopic pregnancy in emergency department patients with abdominal pain or vaginal bleeding. Acad Emerg Med. 2003;10(2):119-126.

50. McRae A, Murray H, Edmonds M. Diagnostic accuracy and clinical utility of emergency department targeted ultrasonography in the evaluation of first-trimester pelvic pain and bleeding: a systematic review. CJEM. 2009;11(4):355-364.

51. Crochet JR, Bastian LA, Chireau MV. Does this woman have an ectopic pregnancy? The rational clinical examination systematic review. JAMA. 2013;309(16): 1722-1729.

52. Hahn SA, Lavonas EJ, Mace SE, Napoli AM, Fesmire FM. Clinical policy: critical issues in the initial evaluation and management of patients presenting to the emergency department in early pregnancy. Ann Emerg Med. 2012;60(3):381-390.

53. Stein JC, Wang R, Adler N, Boscardin J, Jacoby VL, Won G, et al. Emergency physician ultrasonography for evaluating patients at risk for ectopic pregnancy: a meta-analysis. Ann Emerg Med. 2010;56(6): 674-683.

54. Moore C, Todd WM, O'Brien E, Lin H. Free fluid in Morison's pouch on bedside ultrasound predicts need for operative intervention in suspected ectopic pregnancy. Acad Emerg Med. 2007;14(8):755-758.

55. Rodgerson JD, Heegaard WG, Plummer D, Hicks J, Clinton J, Sterner S. Emergency department right upper quadrant ultrasound is associated with a reduced time to diagnosis and treatment of ruptured ectopic pregnancies. Acad Emerg Med. 2001;8(4):331-336.

56. Berghella V, Roman A, Daskalakis C, et al. Gestational age at cervical length measurement and incidence of preterm birth. Obstet Gynecol. 2007;110(2 Pt 1):311-317.
57. Owen J, Yost N, Berghella V, et al. Can shortened midtrimester cervical length predict very early spontaneous preterm birth? Am J Obstet Gynecol. 2004;191(1):298-303.

58. Mella MT, Berghella V. Prediction of preterm birth: cervical sonography. Semin Perinatol. 2009;33(5):317-324.

59. Shah S, Teismann N, Zaia B, et al. Accuracy of emergency physicians using ultrasound to determine gestational age in pregnant women. $\mathrm{Am}$ J Emerg Med. 2010;28(7):834-838.

60. Nalaboff KM, Pellerito JS, Ben-Levi E. Imaging the endometrium: disease and normal variants. Radiographics. 2001;21(6): 1409-1424.

61. Di Salvo DN. Sonographic imaging of maternal complications of pregnancy. J Ultrasound Med. 2003;22(1):69-89.

62. Adhikari S, Blaivas M, Lyon M. Role of bedside transvaginal ultrasonography in the diagnosis of tubo-ovarian abscess in the emergency department. J Emerg Med. 2008;34(4):429-433.

63. Scoutt L, Baltarowich O, Lev-Toaff A. Imaging of adnexal torsion. Ultrasound Clin. 2007;2(2):311-325.

64. Shiver SA, Lyon M, Blaivas M. Detection of metallic ocular foreign bodies with handheld sonography in a porcine model. J Ultrasound Med. 2005;24(10):1341-1346.

65. Shinar Z, Chan L, Orlinsky M. Use of ocular ultrasound for the evaluation of retinal detachment. J Emerg Med. 2011;40(1):53-57.

66. Dubourg J, Javouhey E, Geeraerts T, et al. Ultrasonography of optic nerve sheath diameter for detection of raised intracranial pressure: a systematic review and meta-analysis. Intensive Care Med. 2011; 37(7):1059-1068.

67. Rajajee V, Vanaman M, Fletcher JJ, Jacobs TL. Optic nerve ultrasound for the detection of raised intracranial pressure. Neurocrit Care. 2011;15(3):506-515.

68. Chávez-López MA, Naredo E, Acebes-Cachafeir JC, et al. [Diagnostic accuracy of physical examination of the knee in rheumatoid arthritis: clinical and ultrasonographic study of joint effusion and Baker's cyst]. Reumatol Clin. 2007;3(3):98-100. Spanish.

69. Kane D, Balint PV, Sturrock RD. Ultrasonography is superior to clinical examination in the detection and localization of knee joint effusion in rheumatoid arthritis. J Rheumatol. 2003;30(5):966-971.

70. Chhem RK, Beauregard G. Synovial diseases. Clin Diagn Ultrasound. 1995;30:43-57.

71. Richardson ML, Selby B, Montana MA, Mack LA. Ultrasonography of the knee. Radiol Clin North Am. 1988;26:63-75.

72. Bickerstaff DR, Neal LM, Booth AJ, et al. Ultrasound examination of the irritable hip. J Bone Joint Surg Br. 1990;72(4):549-553.

73. Volberg FM, Sumner TE, Abramson JS, Winchester PH. Unreliability of radiographic diagnosis of septic hip in children. Pediatrics. 1984;74(1):118-120.

74. Adhikari S, Blaivas M. Utility of bedside sonography to distinguish soft tissue abnormalities from joint effusions in the emergency department. J Ultrasound Med. 2010;29(4):519-526.

75. Wiler J, Costantino TJ, Filippone L, Satz W. Comparison of ultrasound-guided and standard landmark techniques for knee arthrocentesis. J Emerg Med. 2010;39(1):76-82.

76. Hind D, Calvert N, McWilliams R, et al. Ultrasonic locating devices for central venous cannulation: meta-analysis. BMJ. 2003; 327(7411):361

77. Costantino TG, Parikh AK, Satz WA, Fojtik JP. Ultrasonographyguided peripheral intravenous access versus traditional approaches in patients with difficult intravenous access. Ann Emerg Med. 2005;46(5):456-461.

78. Nazeer SR, Dewbre H, Miller AH. Ultrasound-assisted paracentesis performed by emergency physicians vs the traditional technique: a prospective, randomized study. Am J Emerg Med. 2005;23(3):363-367.

79. Branney SW, Wolfe RE, Moore EE, et al. Quantitative sensitivity of ultrasound in detecting free intraperitoneal fluid. J Trauma. 1995; 39(2):375-380.

80. Grogan DR, Irwin RS, Channick R, et al. Complications associated with thoracentesis. A prospective, randomized study comparing three different methods. Arch Intern Med. 1990;150(4):873-877. 
Reports in Medical Imaging

\section{Publish your work in this journal}

Reports in Medical Imaging is an international, peer-reviewed, open access journal publishing original research, reports, reviews and commentaries on all areas of medical imaging. The manuscript management system is completely online and includes a very quick and fair peer-review system, which is all easy to use.

Submit your manuscript here: http://www.dovepress.com/reports-in-medical-imaging-journal 